\title{
Using Information Technology in the Administration of Human Capital: A Proposed Model for Public Yemeni Organizations
}

\author{
Fahd Mohammed Saleh Alduais ${ }^{1}$ \\ ${ }^{I}$ (Accounting Department, National Institute of Administrative Sciences, Republic of Yemen)
}

\begin{abstract}
Purpose: To establish a general framework for information technology IT in the public Yemeni organizations PYO, to make a proposed model for database exchange process among the different organizations in the public sector, and to clarify the importance of modern techniques in the administration of human capital HC. Method: the researcher made use of the inductive research method (descriptive-study) for data-collection functioning sources like academic books, and articles in relation to the investigated topic. Results and conclusions: with the increase of the public organizations in Yemen and the collected valuable data, it is prospectively expected that these organizations will depend on the new information technology techniques that include a group of tools working through special connected database programs like, Datawarehouse, Data-mining and OLAP (On-Line Analytical Processing). Hence, such tools could be either of positive or negative reflections depending on its user.
\end{abstract}

Keywords -information technology IT, human capital HC, business intelligence BI, public sector organizations PSO, human resources $H R$

\section{INTRODUCTION AND BACKGROUND}

Human resources' HR duty changes fast as a reaction to socio-environmental, professional and fast development of information technology IT $^{1}$. In other words, fast progress in IT and telecommunications has resulted to a widely open market and participated in both technological research and innovation processes. Due to this, information has become more reachable and at hand to be used as the first choice that an organization should be able to control to get a recognition rank ${ }^{2}$.

Human capital HC is the most important element for performing the duty of HR. HR's duty is represented in the knowledge possessed by professional persons including skills, experiences and innovations ${ }^{3}$. Needles to say, well-administered skills by organizations would participate in making it easy to refer to such sources anywhere and anytime. Besides, IT is the most suitable solution for dealing with large quantity of information; although there are some useable applications in the administration of human capital. However, the major problem in such application is that they are neither updated regularly nor alternative up-to-date applications are made available, especially after the availability of new applications which have made it possible to establish a database that allow storing a large quantity of data - that can be processed, shared with other users and/or organizations at the same time.

As a result of this, it is important to find a model that its outputs are characterized with the characterizations of human intelligence (simulation of some human features of human intelligence). The purpose of this model is making the organizations able to share the use of data in the process of planning and decision-making in regard to HR. A proposed framework model will be introduced in this paper which can be used to exchange data and information among public organizations in the administration of human capital on condition that a central organization like the National Institute of Administrative Sciences in the Republic of Yemen is available and is being deemed responsible for training and qualifying the country staff. This central organization must be given the authority of supervision, database observance, database control, and sending informing letters regarding the training needs (like training courses, programs, and educational courses) for the other organizations. Thus, such needs are really a must for HR in the organizations.

In this paper; however, a number of the raised questions have been accounted for by the researcher as an attempt to reach the stated objectives of the study through a number of sections which will be presented in this paper.

To start with the problem of the investigated issue in this study, today, it is well-known that the public organizations in the Republic of Yemen aim at improving and developing HR using different programs, and both training and educational courses through targeted institutions assigned for training the staff of the public sector. It is also worth mentioning that a well-known institution by financial and administrative training is the National Institute of Administrative Sciences. In spite of this, it is clearly observed that modern technology has not been taken into consideration by those responsible for the administration of human capital — say policymakers. That is to say, the problem is that there seems to be an unrecognized ignorance of the positive effect of 
the modern technology in terms of storing and publishing information, yet being able to restore them for planning and decision-making purposes. On the basis of this, one could ask: is it necessary to make use of the applications of the modern technology in the administration of human capital? Can such new techniques fulfill the desires of its users? And why is the administration of human capital important?

The importance of this research lies in the fact that it is actually an attempt to attract the attention of the public organizations towards adapting complete databases that are based on smart applications participating in altering the accumulated education for all HR's levels into active source that would help the organizations in future in the process of planning human capital and establishing a recognition rank for an organization.

This paper has actually three objectives: 1) establishing a framework for IT in the public Yemeni organizations, 2) proposing a model for the process of exchanging data and information among different organizations in the public sector, and 3) showing the importance of modern techniques in the administration of human capital.

Previous studies about this issues include the study ${ }^{4}$ where in the researchers studied the effects of IT on the experts of HR. The study focused on the dealings between the HR's experts with information and the determined expectations resulting from the increased use of IT. Results of this study indicated that IT provided HR's experts with reaching information yet publishing it efficiently in addition to the effect on what is expected from them.

Another study ${ }^{5}$ which was a case-study for four organizations in Australia supported from Linkage coordinated by Australian Research Council; every organization is considered a member in the administration of Australian Senior Human Resources (ASHR). The study aimed at identifying the role of the HR's computedsystems in the organization strategy which was restricted to the overcome of one or more of three challenges: 1) preservation to organizational awareness, 2) finding solutions for individual related difficulties and, 3) administration of accepting the user's request to change in relation to the system. The results of this research indicated that although using new or updated systems, there is no organizational awareness shown by the chief administration to apply them, and there is also no interest in solving the problems in the system of HR's information in addition to the unavailability of acceptance from chief administrations (main users).

One more study ${ }^{6}$ is that about the effect of IT on HR. It explored the public sector on subjects from directors of HR in the public universities in terms of university states' system in the southern east of USA. The study focused on collecting data in relation to acting computed IT of HR, the expected achieved benefits, degree of satisfaction about it, and finally its strategic effects. The results of the study indicated that the current systems are encouraging, the HR's directors are stratified about the systems, but they have not seen many benefits in spite of realizing the programs' effects on information and on the sharing information, some directors stated the need for adding some modern applications to the current systems to play their role effectively, and some other directors made it certain that such systems are not being fully used.

\section{METHOD}

This study is purely qualitative, descriptive and yet inductive. The researcher presents qualitatively data about the public organizations in the Republic of Yemen. In other words, the researcher proposes descriptively a model of IT that would help in a better and more effective way in the administration of human capital. Positive effects of the use of such proposed model and yet negative effects of keeping the mode of using the traditional strategies in the administration of human capital are all induced.

The setting of the study is the National Institute of Administrative Sciences (presented as a sample leading central organization for the proposed model by the researcher), IBB governorate, Republic of Yemen. The study was conducted between early 2012 (start-date) and early 2013 (end-date).

The subjects of the study are the public organizations in the Republic of Yemen represented through the National Institute of Administration Sciences.

Major terms that are used in this used include:

1. Human capital: it includes acquired and learned skills, abilities, etc. that a certain employee or applicant for employment possesses.

2. Information Technology IT: it refers to a set of tools, devices that work together as a system.

3. Public organizations: it refers and includes all the institutions of public sector in the Republic of Yemen, like the National Institute of Administrative Sciences (NIAS).

4. National Institute of Administrative Sciences: This institute was called the National Institute for General Administration and was coordinated by the North of Yemen before the Unification of Yemen (22 ${ }^{\text {nd }}$, May, 1994). The main branch was in Sana'a with branches in IBB, Taiz, and Hodaidah governorates. In the South of Yemen, it was called Institute of Administrative Sciences and its main branch was in Aden. Having achieved the Unity between the two parts of Yemen, the two institutes have been merged and/or unified under the name of the National Institute of Administrative Sciences (NIAS). The major purpose of this organization is to qualify and train country staff with training programs and 
short courses in the fields of administration and finance and also awarding higher diplomas in general administration (a year program).

\section{BUSINESS INTELLIGENCE APPLICATIONS AND HUMAN CAPITAL}

Developing countries like Yemen - have been able to make use of modern technology following the success of the developed countries. However, the major problem remains that are there any reflections out of this use? This is actually the gap between the developing and developed countries in terms of technology investment.

Using IT requires breaking the ice ${ }^{7}$ and being convinced and aware of the maximum and positive use of it. Yet, all organizations whether commercial, service, or manufacturing aim at achieving a recognition rank in the new international market. Having this in mind, the researcher observed that is worth to show the plus points that characterize some IT and telecommunications applications. For instance, consider the business intelligence applications or sometimes called smart tools and/or applications. In the administration field, the business intelligence can take the form of guide or map of smart data that would allow identifying the weaknesses points in an organization and the improvement chances through a tool for supervising level of risk and decisionmaking.

\subsection{General Layout of IT}

IT and telecommunications include a group in inputs, procedures, tools, and programs that work together to achieve the goals of an organization ${ }^{8}$. IT also includes all discoveries, updates, innovations that are dealt and are dealing with all categories information in terms of its collection, analysis, documentation, storing and restoring at the same time, in the appropriate and possible way ${ }^{9}$. Moreover, IT is defined ${ }^{10}$ as a group of materials and abilities that could be used to create store, publish information and its three basic elements (computers, telecommunication networks, and technical awareness), as illustrated in figure (1).

The figure illustrates the interaction among IT elements with each other to create chances for both individuals and organizations to be producers, effective and successful in general ${ }^{11}$.

In fact, the IT importance cannot be ignored in the organizations especially the provided information by such systems. Consider, for instance, the HR system. It really well-know that such system is responsible for all the matters staff in a certain organization. In other words, it considers: financial, administrative, and intellectual features of HR which are represented by human capital that includes information, experiences, and abilities that the staff have in an organization.

Due to this, it was a must to focus on the human capital's element and attempting the use of modern techniques for its administration. Needless to say, the most important thing that IT has produced in the field of IT administration and the ability to control required information by the beneficiaries is the business intelligence applications. These applications take part actively in collection, analyzing, publishing, and protecting economic and strategic information ${ }^{12}$.

FIGURE (1): Basic elements of information technology IT $^{9}$

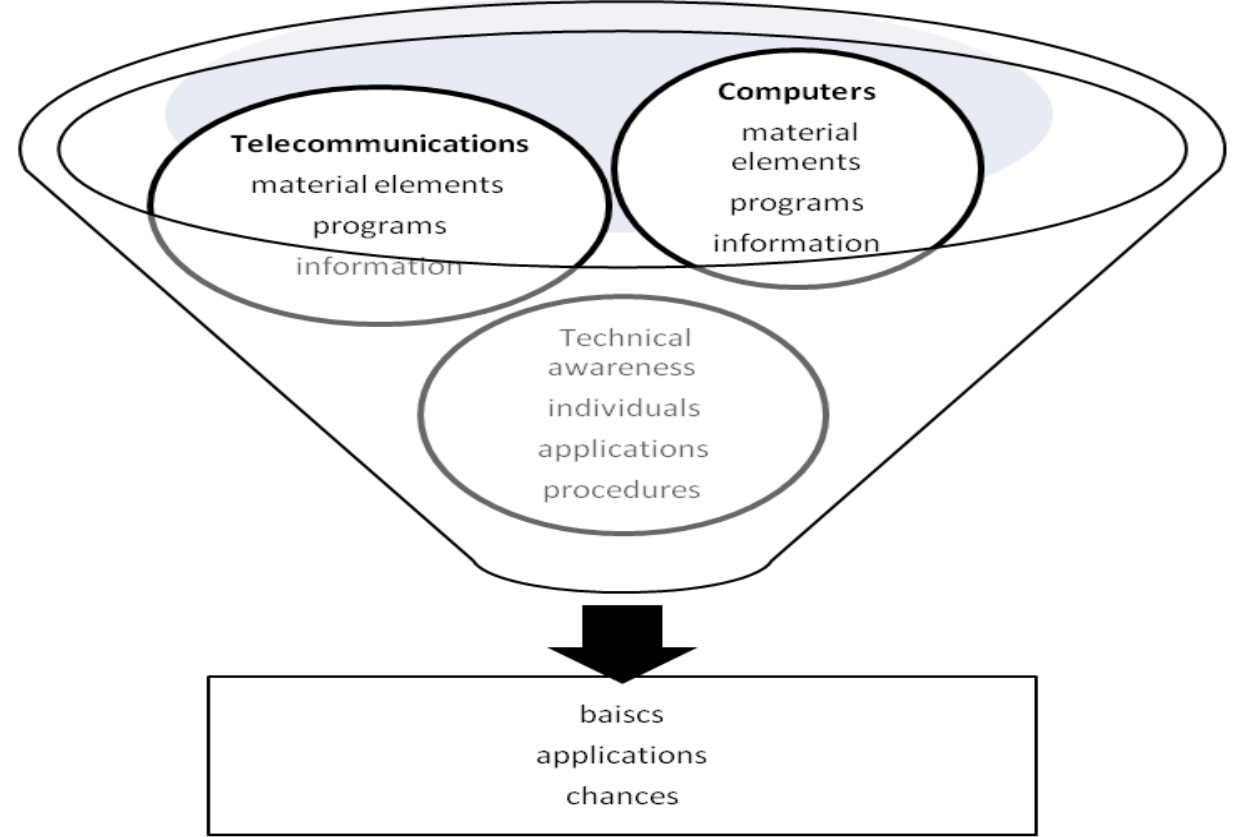




\subsection{Human capital automation}

IT has become widespread as a mean of support for commercial and governmental companies, and non-profit organizations. They have really reached an advanced level in the regard to the electronic operation ${ }^{13}$.

Operation and administration of information using the different IT applications was of interest to the organizations. For instance, it is possible to make use of these techniques in the field of human capital administration in the public organizations represented by information that include skills and information which an individual possesses. The possessed information and skills are altered to essentials referred to as ownedproperty frame as soon as it is saved within the different organizations.

It is worth-mentioning that such information that represents what an individual possesses needs to be gathered, classified so that it can help those of interest—obtaining ready-made reports— enabling them to have a look at human treasure (human capital ) inside their own organization. Besides, it is possible to identify the needs of an individual in terms of training and qualifying in certain skills and/or abilities. This actually leads us to the fact that when collection a lot of data and processing it, the result is such detailed classified information that would help in decision-making and increasing and/or enhancing the competitive factor as well. By this means, one could assume that using business intelligence applications result to better decisions.

Actually, business intelligence considers the effective collecting and use of technology for information to help improving the activities or an organization. Additionally, the business intelligence system is being looked at ideally for it provides the staff of an organization, its partners, and yet its customers with reaching the requested information easily, effectively, and the ability to analyze and share information with others ${ }^{14}$.

Business intelligence could be defined as a group of mathematical models and analysis methods that could make use of available data to generate useful information for the complex processes of decision-making ${ }^{15}$. Business intelligence includes: data-collection, data-storing, information administration, and analysis tools allowing a user to review complex and competitive information for both policy and decision-makers.

\subsubsection{Smart techniques used in the administration of human capital}

Administration can greatly benefit from the introduced features of the use of systems and tools of IT like online analytical processing system, data-mining, data-marts, data-warehouse, data-extract, transform and load, status and analysis, and reports administration. They can be used for supporting the effectiveness and efficiency for planning and and operating the information flow, activities and decisions in the internal and external environment, especially administering the human capital to guarantee achieving competitive feature and systematic strategy.

FIGURE (2): Business intelligence tools platform

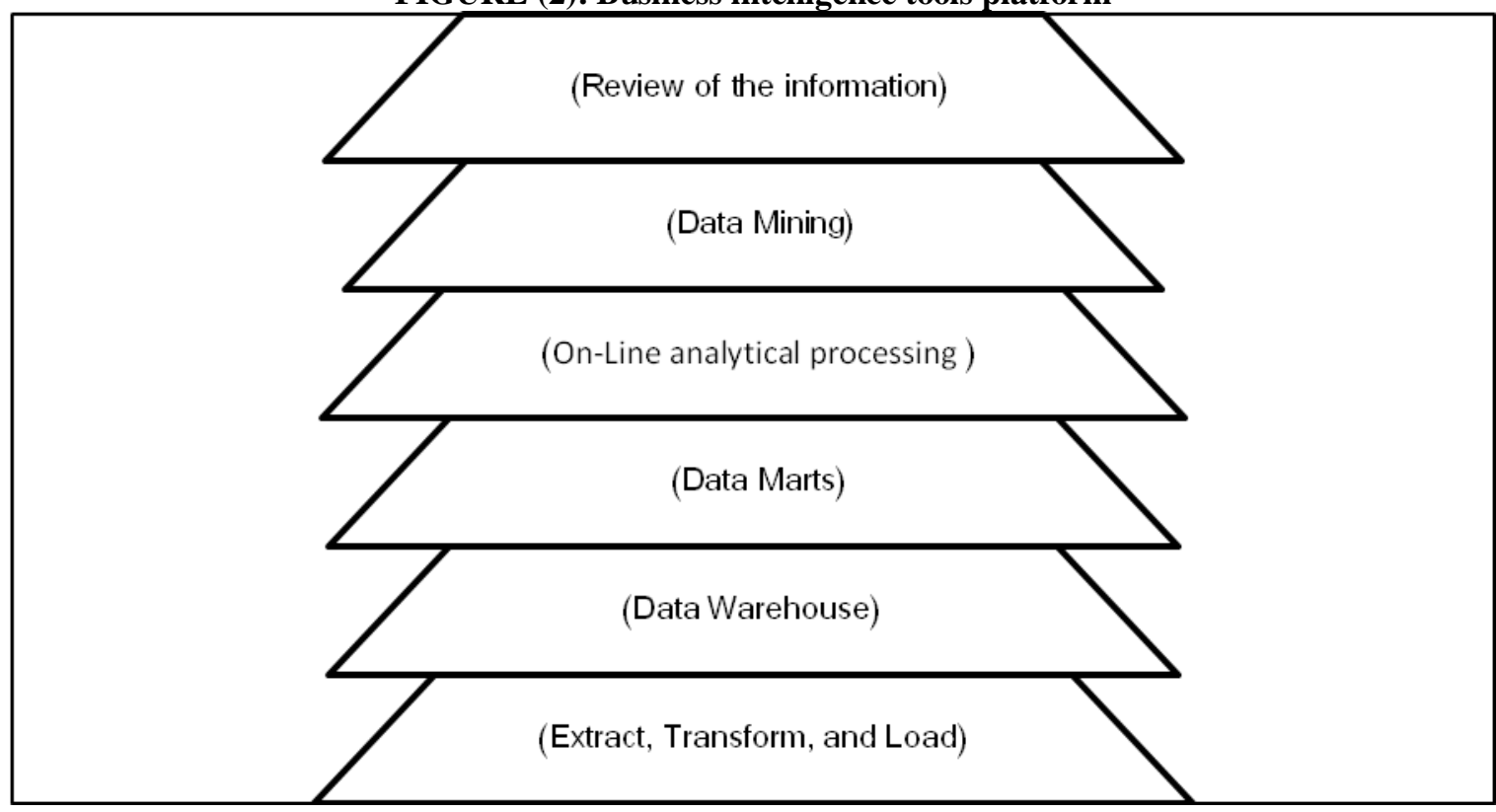

\subsubsection{Extract, transform, and load data}

They include designed tools for extracting data from different sources to be transformed and downloaded to the data-warehouse. This process is referred to as complete-data processing and it is necessary to convert such data to the required copies by the organization regardless of the storing way in the operating environment before transforming the data to the data-warehouse. 


\subsubsection{Data-warehouse}

The data-warehouse stores data for both previous and recent years that is abstracted from previous operating databases for the organizations. It is also considered as a central source of data that would be classified, revised, and unified so that it could be used by directors and other users ${ }^{16}$.

\subsubsection{Data-marts}

It refers to secondary data-warehouses that are used for specified purposes like data related to qualifications, training course, and professional and/or work experiences.

\subsubsection{Online analytical processing}

Online analytical processing (OLAP) is considered as a unique development for processing system compared to the traditional system that is no more suitable for the current advancements of works that require constant update and production of data ${ }^{17,18}$.

\subsubsection{Data-mining}

Improved techniques of data storing and collecting have provided a large quantity of data in different fields. For instance, public sector organizations ${ }^{15}$ where in there a group of activities that participate in the analysis of databases for the purpose of extracting useful information - supporting decision-making. These achievements are contributed to different means including data-mining where in the term (data-mining) indicates the exploration process and analysis of a group of data, usually of large quantity to be used in decisionmaking and problem-solving.

\subsubsection{Review of information}

Having extracted and analyzed the information from the large databases, then such datum are reviewed in reports, dashboards, charts, alerts, and forecasting that would participate in obtaining final information for the final user.

\subsubsection{IT applications costs}

Most of the organizations use some IT models. In spite of this, only few number of these organizations have complete business intelligence systems. Actually, the costs of a business intelligence system could be counted as it follows:

\subsubsection{Hardware cost}

It refers to whole dependence on hard-disks of large size where in data-warehouses can be measured in terabytes. Some other organizations use petabytes (a petabyte equals 1024 terabyte) to establish its ware-houses. In addition to this, server devices that belong to networks are also used for the purpose of data-transform using the intranet and extranet factors.

\subsubsection{Software cost}

Organization responsible for the administration of human capital must provide a complete package of programs that could suite all age levels on the databases and applications be it current or recent. These facilities will provide the business intelligence system with data to be processed later. Moreover, this package should be in agreement with nature of needs in the organization. It goes without saying that the main purpose to get a package of smart tools that could be used in the administration of human capital and/or HR in the various organizations to provide the users with reports about the humans' skills — available in every organization and the possibility of improving such skills with different training course and/or programs.

\subsubsection{Use cost}

The cost of the devices and/or tools is paid once while the cost of the use of such package is a continuous process. That is to say, it includes paid cost for training both current and recent employees in addition to the cost of yearly maintenance and program promotion.

\section{HUMAN CAPITAL MANAGEMENT IN THE IT ENVIRONMENT}

Both administration and planning of $\mathrm{HR}$ aim at ensuring the provision of the required number of employees in the the required suitable qualifications and efficiencies in the suitable time and place - serving the organization's goals ${ }^{19}$. Needless to say, those who are responsible for planning can collect required data and details in a profile that summarizes private information in relation to both current strengths and weaknesses in the progress of the work. 
However, such information might be found in the available databases in the organizations that are working on a system that does not reach the level of tools and application of business intelligence. In other words, there must be at least basic information that would help searching for private information in regard to human capital, yet it takes long time to collect be it from the semi-business intelligence system or the traditional and/or manual system that uses records which actually applies to the majority of the public organizations in Yemen.

\subsection{Planning human capital}

Generally, a plan is the output of the process of planning. Yet, it is considered as a practical guideline to perform and/or apply the plan as it clarifies the timeline steps and stages where efforts are met towards the targeted goal. Needless to say, the manpower plan is not out of this framework; it is a major point in both development and strategic planning for the public organization on all its different levels and sectors ${ }^{20}$.

FIGURE (3): Strategic plan of human capital

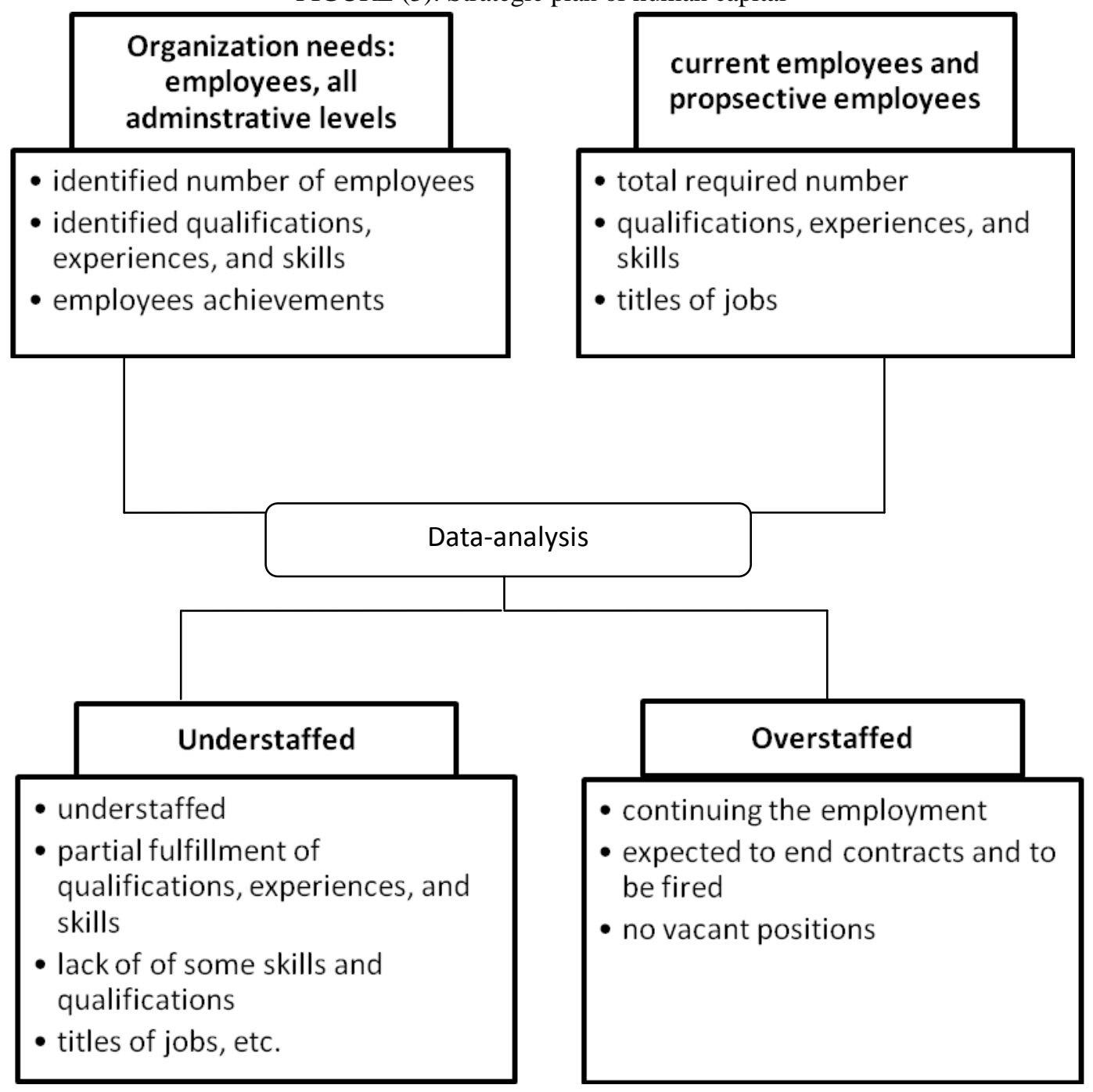

Current organizations with the attitude of improving its competitive rank move towards preparing strategic plans to see if there is any possibility to develop skills and abilities of HR in the organization by identifying their weaknesses. Having done this, then they are qualified in such identified weak points using either training or educational programs. The possibility of looking for prospective employees having skills, and experiences that do not exist in the organization is also considered during this stage.

Figure (3) demonstrates a strategic plan that could be used to make a comparison and analysis of data related to both current and recent human capital. This plan is considered as ready information in the organizations - prepared either manually or simple database programs. However, the question remains that whether such date - is it used in the administration of human capital and realizing the needs for qualifying HR effectively and efficiently, or not? It cannot actually be denied that current databases available in the public 
Yemeni organizations are traditional, yet do not include any smart IT tools or applications which allow datasharing.

In more detail, the public organizations are indeed in need of an official organization and/or centre that deemed responsible for the administration of human capital planning in Yemen. A good example for this could be the National Institute of Administrative Sciences (a pubic institute administered by the Ministry of Vocational and Technical Education). Actually, this institute is currently responsible for offering training courses and programs. However, the institute is not responsible for administration of human capital for all the public organizations. That is to say, when re-considering the role of every organization in the qualification of $\mathrm{HR}$, it is being noticed that such an organization sends its staff randomly, albeit a certain employees has taken more than a course while another has got none. Furthermore, there is no documentation for information relating to human capital in all the public organizations, so they need new tools-helping them achieve effective administration of human capital.

\subsection{Administration of human capital using IT smart applications} figure 4.).

In this area, an organization could invest the ongoing development of IT in relation to databases, (See

Figure (4) presents how data from different sources is obtained, stored, and re-stored for analysis. Technically, IT smart applications work in practical steps: data-integrate (extract, download, and transform data), data-store, and data-use as illustrated in the figure. The first step is considered as the most important one among the other steps ${ }^{11}$.

The first step in data-integrate is including a group of primary activities that work in obtaining data from multi-sources; downloaded, and then transformed into the data-warehouse. The second step is storing all data centrally in the data-warehouse. After that, the data is transformed into the data-marts to be available for the final user according to the type of information, e.g. dividing human capital in terms of position level, qualifications, attended training courses, etc. the last step includes a group of tools which participate in the process of research for required information by the user like data-mining. There are also facilitating tools within this step including dashboards, alerts, and reports.

Using the model provided in figure (4), the three stages could be applied: data-integrate, data-store, and data-use in the public organizations for collecting data about human capital. To make it clear, support that we have the central organization represented by the (PC) in figure (4) which is responsible for training and qualifying HR and organization $(1,2,3)$ and PCs $(1,2,3)$ respectively. Before starting the first stage, first data is entered, in the available database in PC (1) in the organization (1), PC (2) in organization (2), and PC (3) in organization (3). This step is a must for a proper work of the proposed model. Data, then, is obtained from the central organization, downloaded, and transformed into the data-warehouse where it is stored centrally. Minor data can then be obtained from the data-marts after being transformed into the data-warehouse. The data is then processed, analyzed and reviewed using a group of tools like data-mining, dashboard, and reports.

The model aims at connecting the public organizations to a central organization that would be deemed responsible for training and qualifying. In this case, the National Institute of Administrative Sciences is proposed as a model to take this responsibility, in cooperation with the Ministry of Civil Service. This proposed model will facilitate in qualifying and training HR in all the public Yemeni organizations by collecting all related data in relation to human capital for all the organizations. Not only doing so, but they also need to perform data-classification, identifying effective needs at the organizations' level in general and administrative levels and individuals in particular.

Besides, the model provides the facility of data-review by the different public organizations at the same time to know all information related to human capital. 
FIGURE (4): Human capital administration model in the public Yemeni organizations

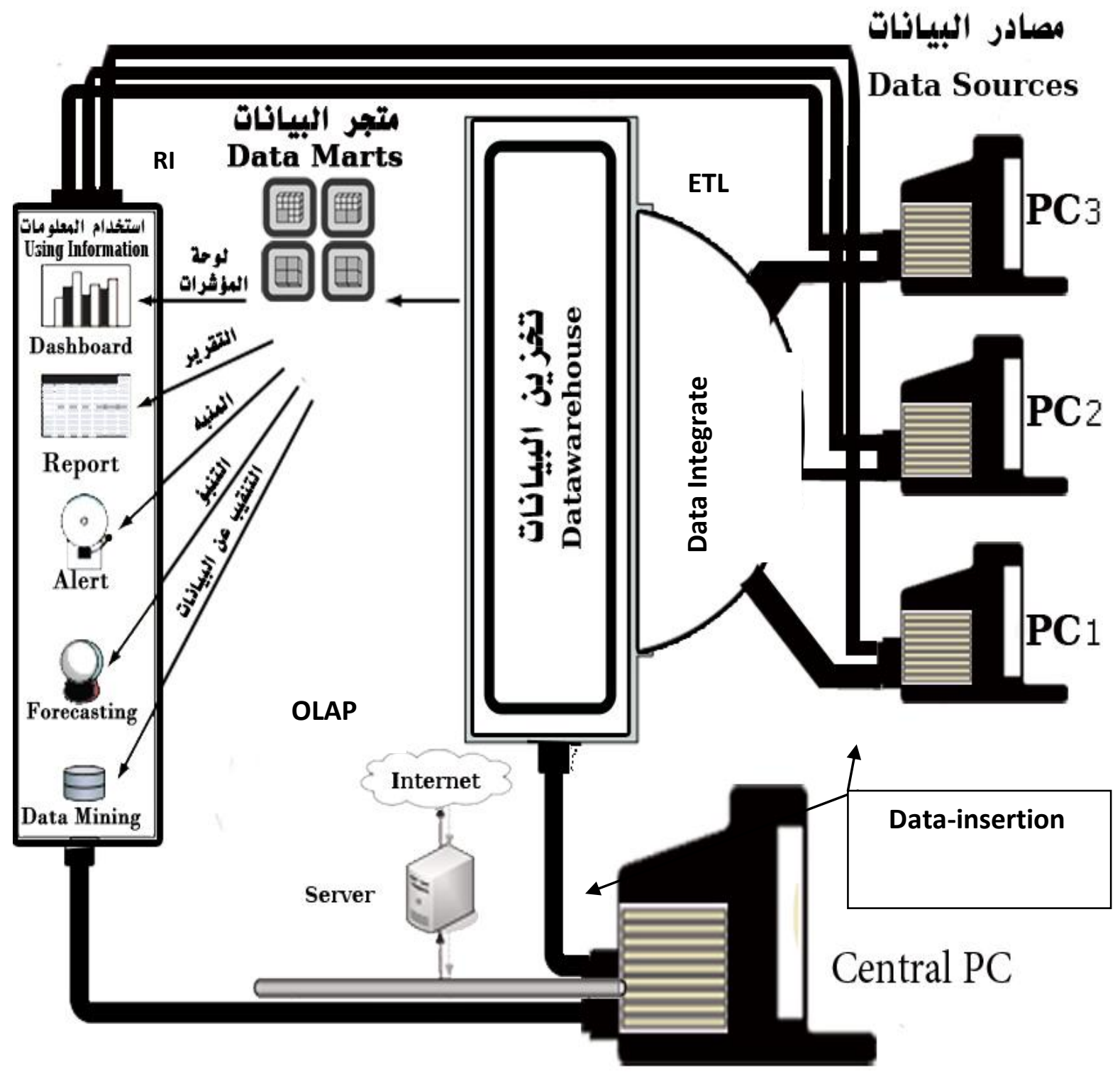

\subsubsection{Data-sharing}

Table (1) shows some abilities that would participate in achieving information share process of human capital in the public organizations.

TABLE (1): Group sharing of abilities in knowledge administration

\begin{tabular}{|l|l|}
\hline \multicolumn{1}{|c|}{ Ability } & \multicolumn{1}{c|}{ Description } \\
\hline Publishing & $\begin{array}{l}\text { Importing documents with the ability to work simultaneously on the same } \\
\text { document by different users, yet the ability to check/track occurring changes } \\
\text { to the document }\end{array}$ \\
\hline Review and response & Reviewing data and updating it on the computers and servers \\
\hline Tracking discussion & Organization discussions for different users about different issues \\
\hline Documents administration & Storing information for different types of programs in the database \\
\hline Security & Data-protection, no log in for those who do not have usernames \\
\hline adequacy & $\begin{array}{l}\text { Users can log in for the system of their own organization from anywere } \\
\text { outside the organization }\end{array}$ \\
\hline Improving applications & $\begin{array}{l}\text { It is possible to improve the programs and applications through previous } \\
\text { made programmed system to serve this purpose }\end{array}$ \\
\hline Work-share tools & $\begin{array}{l}\text { Internal and external networks, internet, email, video and audio-based } \\
\text { conferences }\end{array}$ \\
\hline
\end{tabular}




\subsubsection{Difficulties of applying the proposed model}

According to ${ }^{5}$, there are three difficulties that hinder achieving the participations introduced by computed IT system of HR for the organization's strategy. These difficulties are: 1) general directors' are not showing systematic awareness, 2) there is no tendency towards changing the traditional systems and replacing them with recent ones, and 3) inability to find solutions for problems which occur in the HR's systems.

Another study concluded ${ }^{21}$ that the success of applying such systems which depend on recent smart applications is based on a group of major factors: support of general directors, clear strategic goals, strategic adequacy between system and other procedures, guaranteeing accuracy of data, and infrastructure availability. Hence, such positive factors could be turn to negative ones when they are not provided and/or achieved.

With the reference to the above mentioned studies, difficulties that could hinder the application of the proposed model in this study include, but are not limited to:

1. Decision-makers and/or general directors are not really aware of the importance of such programs;

2. Decision-makers and/or general directors are not really convinced with what such IT applications can introduce;

3. There is no interest in updating and promoting systems and programs in the case of application;

4. The occurring problems while using the IT of HR are not dealt with seriously and promptly;

5. There is no suitable environment for applying the proposed model for all the public organizations;

6. There is no suitable infrastructure to apply the proposed model.

\subsection{The importance of IT in the administration of human capital in the public organizations}

The importance of human capabilities increases consecutively with fast changes that appear in different sectors: manufacturing, commerce, and service). This occurs because human capital is the basic tool for causing any changes. For that matter, the administration of HR should aim at achieving the competitive ability for the company in the field of HR by providing educational and training programs to serve individual development for the employees.

\subsubsection{Modern techniques advantages}

A study ${ }^{16}$ concluded that directors are greatly benefiting from the use of databases when storing data, restoring data, data administration, detecting frequently repeated data in more than a system, supporting the process of data-share feature, simplifying and ordering dealings, organizing entering different administrative levels to obtain data according to hold positions with securing the use process, and supporting and enhancing the used databases by the organization.

Moreover, technology is being increasingly used in a group of various ways to support the activities of HR. It also gives the experts of HR more time for more strategic matters where in some of this time is spent to assess the activities of human capital which is enhanced by using advanced technology.

\subsubsection{Effectiveness and efficiency of modern techniques in the administration of human capital}

Development of human capital has become a priority for organizations. In other words, this achievement is a gain for HR by gaining new information be it through education or training in the different assigned institutions as the National Institute of Administrative Sciences in the Republic of Yemen (it qualifies public sector staff). At the same time, this achievement also is a non-capital investment to reach unconsidered matters that could vanish by death of a certain employee or moving him/her to another organization.

The wide development which is clearly observed in nowadays in the public organizations especially in the administrative structure and the tendency towards system-based administration are all factors that have lead to what is called IT of HR. As a result of this, directors and users either inside or outside the organization show their interest in obtaining information in relation to such resources (mostly abstract-human capital) and extracting, analyzing and possibility of storing and using the data in anywhere at anytime.

By this means, there is a satisfaction that traditional means-helping in storing data and then processing it simply to get information is becoming gradually useless. These services include the use of some Office programs (software), some databases programs (hardware) which do not depend on storing data in large space and online extract and download of data as in the used tools in business intelligence.

Thus, when applying the modern techniques in the administration of human capital for many organization, these organizations can share information at the same time, provide training programs and course for developing HR in all organization, administer such collected data, store it and prepare it logically to be presented in report-formats that would $\mathrm{b}$ used by directors and other beneficiaries in all other organizations.

\section{CONCLUSION}

This inductive, descriptive study (say pilot study) aimed at proposing a model that promotes the administration of human capital using IT and business intelligence applications. However, it is expected that 
public organizations in the Republic of Yemen will start yet encourage the use of IT modern techniques which include a group of tools working on the basis of certain programs like OLAP, Data-warehouse, Data-mining, etc. Needless to say, such positive tools could be either positive or negative according to its users.

Both simplicity and clearness in the applications must be approved by the organizations considering costs, and infrastructure for telecommunications. The organization should also adopt the use of such applications for its proper use and serving the needs of the organizations rather than making complex procedures and applications that are of use to the organization. Security and supervision should be also considered in addition to making the applications available for all local and international organizations. Most importantly, such collected data would be that its user could reach effective indications for improving the level of administration.

One could also infer that the public organizations in Yemen will not be able to improve themselves especially in regard to HR unless they are making use of the amazing ability of computers and document information of human capital that would support the organizations in decision-making and other strategic matters.

Last but not the least, having the modern applications of IT and business intelligence, the extracted traditional information using the traditional programs is now no more than basic input for the IT-based applications. This is actually achieved because the IT-based programs and applications are more efficient for they allow an organization to use the available resources fruitfully and effectively.

\section{Acknowledgements}

The author would like to express his gratitude to Mr. Fawaz Nahshal who greatly helped in the design of the presented figures in this study. Thanks are also due to Mr. Abdullah Alduais and Mr. Ahmed Alduais for their help in the proofreading of this paper and translation matters.

\section{REFERENCES}

[1] Kashive, N. (2011). Managing Today's Workforce: Human Resource Information System (HRIS), its Challenge and Opportunities. International Journal of Research in Finance \& Marketing, Vol. 1 (No. 6), 38-66.

[2] Audigier, M., Couon, G., \& Rassat, P. (2003). L'intelligence économique :un nouvel outil de gestion. Paris: Maxima.

[3] Nagm, N. A. (2009). Management and Electronic Knowledge. Amman, Jordon: Dar Alyazoury Press and Publishing.

[4] Gardner, S., P. Lepak, D., \& M. Bartolc, K. (2003). Virtual HR: The impact of information technology on the human resource professional. Journal of Vocational Behavior, 63, 159-179.

[5] Grant, D., Dery, K., Hall, R., Wailes, N., \& Wiblen, S. (2006). Human Resource Information Systems (HRIS): An Unrealised Potential. The Institute Building (H03), The University of Sydney. Australia: Australian Research Council Linkage Grant (LPLP0882247) in collaboration with the Australian Senior Human Resources Roundtable.

[6] Beadles II, N. A., Lowery, C. M., \& Johns, K. (2005). The Impact of Human Resource Information Systems: An Exploratory Study on the Public Sector. Communications of the IIMA , 5 (4), 39-46.

[7] Hagar, A. E. (2010). Accounting Information System. Sana'a, Yemen: Ala'meen Publishing and Distributing.

[8] Zanella, P., \& Ligie, Y. (2005). architecture et technologie des ordinateurs. Paris: Dunod.

[9] Qendilgy, A. I., \& Alsamara'ai, E. F. (2009). Information Technology and Its Applications. Amman, Jordon : Alwarraq Press and Publishing.

[10] Alsabagh, E. A. (2002). Information Science (1st ed.). Amman, Jordon: Dar Althakafah Bookstore Publishing and Distribution.

[11] Stefănescu, A., Stefănescu, L., \& Ciora, L. I. (2009). Intelligent Tools and Techniques for Modern Management. Chinese Business Review, Volume 8, Number2, 8 (2), 46-54.

[12] Massé, G., \& Thibaut, F. (2001). Intelligence économique: un guide pour une économie de l'intelligence (éd. 1er édition). Bruxelles: De boeck uneversité.

[13] Ballard, C., Abdel-Hamid, A., Frankus, R., Hasegawa, F., Larrechart, J., Leo, P., et al. (2006). Improving Business Performance Insight . . .with Business Intelligence and Business Process Management. International Business Machines Corporation.

[14] Khan, R. A., \& Quadri, S. K. (2012). Dovetailing of Business Intelligence and Knowledge Management:An Integrative Framework. Information and Knowledge Management, 2 (4), 1-6.

[15] Vercellis, C. (2009). Business Intelligence: Data Mining and Optimization for Decision Making (1 ed.). Politecnico di Milano, Italy: John Wiley \& Sons, Ltd.

[16] Mursi, N. M. (2006). Administrative Information System. Eskandriah, Eygpt: Modern University Office.

[17] Yaseen, S. G. (2005). Electronic Administration and Persectives of its Arabic Applications. Riyadh, Saudi Arabia: Institute of General Administration, General Management for Press and Publishing.

[18] Alsamara'ai, S. A., \& Alokaidy, A. A. (2012). Future of Business Intelligence in the Light of Computer Revolution. 11th annual scientific conference of Business Intelligence and Knowledge Economy (pp. 323-344). Amman: Alzaitounah University.

[19] Jackson, G. A., \& Matheuz, R. A. (2009). Administration of Humna Resources. (M. Fatouh, Trans.) Halab, Syria: Shoa'a for Publishing and Science.

[20] Alkebaisy, A. K. (2005). Management of Human Resources in Civil Service. Cairo, Eygpt: Arabic Organization for Administrative Development.

[21] Yaseen, S. G. (2009). Information System of Management. Amman, Jordon: Dar Alyazoury for Publishing and Distribution. 